\title{
AM404, paracetamol metabolite, prevents prostaglandin synthesis in activated microglia by inhibiting COX activity
}

Soraya Wilke Saliba ${ }^{1,2^{*}}$, Ariel R. Marcotegui ${ }^{3}$, Ellen Fortwängler ${ }^{1}$, Johannes Ditrich ${ }^{1}$, Juan Carlos Perazzo ${ }^{3}$, Eduardo Muñoz ${ }^{4}$, Antônio Carlos Pinheiro de Oliveira ${ }^{5}$ and Bernd L. Fiebich ${ }^{1^{*}}$

\begin{abstract}
Background: N-arachidonoylphenolamine (AM404), a paracetamol metabolite, is a potent agonist of the transient receptor potential vanilloid type 1 (TRPV1) and low-affinity ligand of the cannabinoid receptor type 1 (CB1). There is evidence that AM404 exerts its pharmacological effects in immune cells. However, the effect of AM404 on the production of inflammatory mediators of the arachidonic acid pathway in activated microglia is still not fully elucidated.

Method: In the present study, we investigated the effects of AM404 on the eicosanoid production induced by lipopolysaccharide (LPS) in organotypic hippocampal slices culture (OHSC) and primary microglia cultures using Western blot, immunohistochemistry, and ELISA.

Results: Our results show that AM404 inhibited LPS-mediated prostaglandin $\mathrm{E}_{2}\left(\mathrm{PGE}_{2}\right)$ production in OHSC, and LPS-stimulated $\mathrm{PGE}_{2}$ release was totally abolished in OHSC if microglial cells were removed. In primary microglia cultures, AM404 led to a significant dose-dependent decrease in the release of $\mathrm{PGE}_{2}$, independent of TRPV1 or CB1 receptors. Moreover, AM404 also inhibited the production of $\mathrm{PGD}_{2}$ and the formation of reactive oxygen species (8-iso-PGF 2 alpha) with a reversible reduction of COX-1- and COX-2 activity. Also, it slightly decreased the levels of LPS-induced COX-2 protein, although no effect was observed on LPS-induced mPGES-1 protein synthesis.
\end{abstract}

Conclusions: This study provides new significant insights about the potential anti-inflammatory role of AM404 and new mechanisms of action of paracetamol on the modulation of prostaglandin production by activated microglia.

Keywords: AM404, Acetaminophen, Microglia, Inflammation, Prostaglandins, Cyclooxygenase

\section{Background}

Acetaminophen (N-acetyl-para-aminophenol or paracetamol) was introduced in the market more than a century ago. This compound is one of the most common prescribed and over-the-counter (OTC) drugs in the world, although its mechanism of action is not fully understood. It has been shown that acetaminophen has good analgesic and antipyretic properties, but a weak anti-inflammatory activity, inhibiting the prostaglandin synthesis in the central nervous system (CNS) [1], but not peripherally [2].

\footnotetext{
*Correspondence: soraya.wilke.saliba@uniklinik-freiburg.de; bernd.fiebich@uniklinik-freiburg.de

${ }^{1}$ Department of Psychiatry and Psychotherapy, Laboratory of Translational Psychiatry, Faculty of Medicine, Medical Center - University of Freiburg, Hauptstr. 5, 79104 Freiburg, Germany

Full list of author information is available at the end of the article
}

Acetaminophen undergoes a deacetylation to $p$-aminophenol not only in the liver but also in the CNS [3]. In the CNS, p-aminophenol is conjugated with arachidonic acid by the fatty acid amide hydrolase (FAAH) to produce $N$-arachidonoylphenolamine (AM404) [3-5]. It has been suggested that AM404 may be responsible for the analgesic mechanism of paracetamol [3, 6, 7].

The pharmacokinetics of AM404 formation in the CNS after acetaminophen administration has been studied by two different groups, Högestätt et al. [3] and Murasamatsu et al. [7]. Högestätt and collaborators have shown after 20 min of intraperitoneal injections of acetaminophen $(30,100$, and $300 \mathrm{mg} / \mathrm{kg})$ or p-aminophenol $(10,30$, and $100 \mathrm{mg} / \mathrm{kg}$ ), these compounds were converted to AM404 at the doses of $0.14,1.6$, and $10.3 \mathrm{pmol} / \mathrm{g}$ and 3.2, 
44, and $667 \mathrm{pmol} / \mathrm{g}$, respectively [3]. Murasamatsu et al. (2016) demonstrated the conversion of acetaminophen in AM404 in rats treated orally with acetaminophen $(20 \mathrm{mg} /$ $\mathrm{kg}$ ), and the peak of AM404 concentration was $150 \mathrm{pg} / \mathrm{g}$ at the half-life value of $0.3 \mathrm{~h}$.

AM404 is a potent agonist of the transient receptor potential vanilloid type 1 (TRPV1) [8], a low-affinity ligand of the cannabinoid receptor type 1 (CB1) $[3,9]$, and an anandamide membrane transporter (AMT) blocker [10, 11]. Furthermore, it has been shown that AM404 induces hypothermia [12, 13] and analgesia in animal models [14-16].

Some studies have demonstrated the effect of AM404 in modulating inflammation and oxidative stress. Its effects on reducing oxidative stress have been associated with the presence of a phenolic group in its structure [17, 18]. AM404 decreased the production of the cytokines interleukin (IL)-1 $\beta$ and IL-6 and increased in circulating tumor necrosis factor (TNF)- $\alpha$ levels in a murine model of inflammation induced by LPS injection [19]. In a rat model of neuropathic pain, AM404 prevented the overproduction of nitric oxide (NO) and TNF- $\alpha$ and increased IL-10 production [14]. Furthermore, this acetaminophen metabolite inhibited the prostaglandin (PG) $\mathrm{E}_{2}$ formation and the activity of isolated cyclooxygenase (COX)-1 and COX2 enzymes ex vitro, and in RAW264.7 macrophages [3]. In human T cells, AM404 is a potent inhibitor of T cell receptor (TCR)-mediated $\mathrm{T}$ cell activation and specifically inhibited both IL- 2 and TNF- $\alpha$ gene transcription and TNF- $\alpha$ protein synthesis in CD3/CD28-stimulated Jurkat $\mathrm{T}$ cells in a FAAH independent way regulating the activation of the transcription factors NF- $\mathrm{kB}$, NFAT, and AP-1 [20]. In an animal model, it has been shown to inhibit both isoforms of prostaglandin endoperoxide synthase/ cyclooxygenases (PGHS/COX-1 and -2) [21].

Although there are few studies suggesting that AM404 modulates inflammation, the effects of AM404 on the production of members of the arachidonic acid pathway in activated microglia and brain tissues have not been elucidated in detail, possible explaining some mechanism of actions of acetaminophen in the CNS. We therefore investigated the effects of AM404 on the production of eicosanoids induced by LPS in organotypic hippocampal slice cultures (OHSC) and activated primary microglia.

\section{Methods}

\section{Reagents}

AM404 was obtained from Tocris Biosciences (Ellisville, MO) and dissolved in dimethyl sulfoxide (DMSO - Merck KGaA, Darmstadt, Germany) to get a $50 \mathrm{mM}$ stock solution. Further dilutions in DMSO were prepared immediately before the stimulation. AM251 (CB1 antagonist) and capsazepine (TRPV1 antagonist) (Tocris Biosciences) were dissolved in DMSO. LPS from Salmonella typhimurium (Sigma-Aldrich, Taufkirchen, Germany) was resuspended in Dulbecco's Phosphate Buffered Saline (DPBS; Gibco by Life Technologies, Germany) as $5 \mathrm{mg} / \mathrm{mL}$ stock and was used at a final concentration of $10 \mathrm{ng} / \mathrm{mL}$ in the microglial culture and $100 \mathrm{ng} / \mathrm{mL}$ in OHSC. Solvent concentration in the culture media was maintained at $0.1 \%$.

\section{Preparation of organotypic hippocampal slice cultures (OHSC)}

OHSC of C57Bl/6 wild-type (WT) mice were prepared as previously described [22]. In brief, 2 to 3 days old animals, under sterile conditions, were decapitated; the hippocampi were dissected and placed in a tissue chopper $\left(\right.$ McIlwain $^{\mathrm{TM}}$ ) for the preparation of $350 \mu \mathrm{m}$ slices. The slices were transferred to a $0.4 \mu \mathrm{m}$ culture plate inserts (Millipore, PICM03050). Each insert containing 6 slices were placed in a six-well culture plate containing $1 \mathrm{~mL}$ of culture medium $[0.5 \times$ minimum essential medium (MEM), 25\% horse serum, $25 \%$ basal medium without glutamate (BME), $2 \mathrm{mM}$ glutamax, and $0.35 \%$ glucose]. Then, the slices were incubated at $35{ }^{\circ} \mathrm{C}$ in humidified atmosphere with 5\% $\mathrm{CO}_{2}$ (Heracell 240i, Thermo Scientific). The culture medium was changed after the first day of preparation following every 2 days. After 1 week, the slices were pre-incubated with DMSO $0.1 \%$ or AM404 $50 \mu \mathrm{M}$ [23] for $30 \mathrm{~min}$ and then stimulated with LPS for $24 \mathrm{~h}$.

\section{Depletion of microglia from slices culture}

For the depletion of the microglia from the slice cultures, 1:10 of liposome-encapsulated clodronate (Lip-CL - Merck Chemicals GmbH, Darmstadt, Germany) solution $(0.5 \mathrm{mg} / \mathrm{mL})$ was used. After preparation of OHSC, as described above, the slices were incubated overnight $\left(35{ }^{\circ} \mathrm{C}\right.$ in humidified atmosphere with $5 \% \mathrm{CO}_{2}$ - Heracell 240i, Thermo Scientific) with culture medium containing Lip-CL. Then, slices were rinsed in DPBS at $35{ }^{\circ} \mathrm{C}$ and cultured in standard culture medium for another 6 days [22]. This procedure reduces the microglia population to less than $5 \%$, but it does not affect the astrocytes and neuron cells [22, 24].

\section{Immunohistochemistry}

After 1 week of OHSC preparation (wild-type--WT or microglia depleted--Lip-CL), OHSC were washed with DPBS followed by $4 \%$ paraformaldehyde (PFA) incubation for $1 \mathrm{~h}$. After fixation, the slices were washed with DPBS and incubated with 5\% normal goat serum (NGS Vector) in DPBS containing 0.3\% Triton X-100 (DPBS ${ }^{+}$) for at least $2 \mathrm{~h}$. Subsequently, the slices were incubated overnight with mouse anti-GFAP (1:1000, Cell signaling), anti-rabbit-Iba-1 (1:1000, Wako), and DAPI (1:1000, Sigma) in $1 \% \mathrm{NGS} / \mathrm{DPBS}^{+}$at $4{ }^{\circ} \mathrm{C}$. Then, slices were incubated with the secondary antibodies for $2 \mathrm{~h}$ at room temperature. Rabbit highly cross-adsorbed AlexaFluor 594, and mouse AlexaFluor 488 secondary antibody 
(Invitrogen, Carlsbad, CA, USA) was used to detect Iba-1 or GFAP, respectively. Slices were imaged in a Zeiss microscope (Zeiss, Oberkochen, Germany).

\section{Primary rat and mouse microglial cell culture}

Primary mixed glial cell cultures were prepared from cerebral cortices of 1-day neonatal Sprague-Dawley rats or C57Bl/6 mice or $\mathrm{TPRV}^{-/-}$knockout mice, as described previously $[25,26]$. Briefly, $7-13$ forebrains were removed, homogenized, and filtered through a $70-\mu \mathrm{m}$ cell strainer (BD biosciences, Heidelberg, Germany), under sterile conditions. After centrifugation (1000 rpm, $10 \mathrm{~min})$, cells were collected and resuspended in Dulbecco's Modified Eagle's Medium (DMEM) containing 10\% fetal calf serum (Biochrom AG, Berlin, Germany) and antibiotics (40 U/mL penicillin and $40 \mu \mathrm{g} / \mathrm{mL}$ streptomycin, both from PAA Laboratories, Linz, Austria) and cultured $\left(5 \times 10^{5}\right.$ cells/plate $)$ on 10-cm cell culture dishes (Falcon, Heidelberg, Germany) in $10 \% \mathrm{CO}_{2}$ at $37{ }^{\circ} \mathrm{C}$ (Heracell 240i, Thermo Scientific). Floating microglia were harvested every week ( $2-7$ weeks) and re-seeded into $75 \mathrm{~cm}^{2}$ culture flask to give pure microglial cultures. On the next day, medium was changed to remove non-adherent cells, and after $1 \mathrm{~h}$, the cells were stimulated for respective experiments.

\section{Cytotoxicity assay}

Cytotoxicity assay was performed using CellTox ${ }^{\mathrm{Tm}}$ Green Cytotoxicity assay kit (Promega, Mannheim, Germany). Briefly, cells were cultured in 96-well plates at the density of $25 \times 10^{3}$ cells/well in DMEM medium containing 10\% fetal calf serum (Biochrom AG, Berlin, Germany) and antibiotics $(40 \mathrm{U} / \mathrm{mL}$ penicillin and $40 \mu \mathrm{g} / \mathrm{mL}$ streptomycin, both from PAA Laboratories, Linz, Austria). Cells were pre-treated with different concentrations of AM404 $(0.1-10 \mu \mathrm{M})$ or DMSO $0.1 \%$ for $30 \mathrm{~min}$. Thereafter, cells were incubated with or without LPS for the next $24 \mathrm{~h}$. Ethanol (10\% end conc., Sigma-Aldrich, Taufkirchen, Germany) was used as positive control to induce the cell death. After incubation $\left(10 \% \mathrm{CO}_{2}\right.$ at $37{ }^{\circ} \mathrm{C}$ - Heracell $240 \mathrm{i}$, Thermo Scientific), $100 \mu \mathrm{l}$ of CellTox ${ }^{\text {mix }}$ Green reagent were added in each well. The plate was mixed for $1 \mathrm{~min}$ and incubated for $15 \mathrm{~min}$ at room temperature, and the fluorescence was measured at $490 \mathrm{~nm}_{\mathrm{Ex}} / 530 \mathrm{~nm}_{\mathrm{Em}}$ using a Modulus ${ }^{\mathrm{nt}}$ II Microplate Multimode Reader (Turner BioSystems, USA).

The principle of the assay is to evaluate the alterations in the membrane integrity, using the cyanine dye. The dye binds in the dead-cell DNA and enhanced the fluorescent property, which is excluded from viable cells. The fluorescence intensity values obtained were normalized and presented as the percentage of untreated controls.
Determination of prostaglandin (PG) $\mathrm{D}_{2}, \mathrm{PGE}_{2}$, and 8-iso-prostaglandin $\mathrm{F}_{2 a}$ (8-iso- $\mathrm{PGF}_{2 a}$ ) release by enzyme-linked immunosorbent assay (ELISA)

Microglial cells were pre-treated for $30 \mathrm{~min}$ with different concentrations of AM404 $(0.1-10 \mu \mathrm{M})$ or DMSO $0.1 \%$. Thereafter, LPS $(10 \mathrm{ng} / \mathrm{mL})$ was added for $24 \mathrm{~h}$. Supernatants were harvested, and levels of $\mathrm{PGE}_{2}$ (Assay Designs Inc., Ann Arbor, MI, USA; distributed by Biotrend, Cologne, Germany), $\mathrm{PGD}_{2}$, and 8-iso- $\mathrm{PGF}_{2 \alpha}$ (Cayman Chemicals, Ann Arbor, Michigan, USA) were measured by enzyme immunoassay (EIA) in the medium according to the manufacturer's instructions. Standards from 7.8 to $500 \mathrm{pg} / \mathrm{mL}, 78$ to $10,000 \mathrm{pg} / \mathrm{mL}$, and 3.9 to $500 \mathrm{pg} / \mathrm{mL}$ were used for $\mathrm{PGE}_{2}$ (detection limit of $3.25 \mathrm{pg} / \mathrm{mL}$ ), $\mathrm{PGD}_{2}$ (detection limit of $200 \mathrm{pg} / \mathrm{mL}$ ) and 8-iso-PGF ${ }_{2 \alpha}$ (detection limit of $2.7 \mathrm{pg} / \mathrm{mL}$ ), respectively. Data was normalized to LPS and presented as percentage of change in PGs levels of at least three independent experiments.

\section{Western blot analysis}

For COX-2 and mPGES-1 immunoblotting, microglial cells were left untreated or treated with LPS $(10 \mathrm{ng} / \mathrm{mL})$ in the presence or absence of AM404 $(0.1-10 \mu \mathrm{M})$ for $24 \mathrm{~h}$. Cells were washed with cold phosphate buffered saline (PBS) and added lysis buffer $(42 \mathrm{mM}$ Tris- $\mathrm{HCl}$, $1.3 \%$ sodium dodecyl sulfate, $6.5 \%$ glycerin, $100 \mu \mathrm{M}$ sodium orthovanadate, and $2 \%$ phosphatase and protease inhibitors). Protein estimation was measured using the bicinchoninic acid method (BCA protein determination kit from Pierce, distributed by KFC Chemikalien, Munich, Germany) according to manufacturer's instructions and bovine serum albumin (BSA, Sigma) used as a standard. For Western blotting, $20 \mu \mathrm{g}$ of total protein from each sample were subjected to sodium dodecyl sulfate-polyacrylamide gel electrophoresis (SDS-PAGE) under reducing conditions. Then, proteins were transferred onto a polyvinylidene fluoride (PVDF) membrane (Merck Millipore, Darmstadt, Germany) by semi-dry blotting. The membrane was blocked for $1 \mathrm{~h}$ at room temperature using Rotiblock (Roth, Karlsruhe, Germany) and incubated with the primary antibody overnight. Primary antibodies were goat anti-COX-2 (M19, 1:500, Santa Cruz Biotechnology, CA, USA), rabbit antimPGES-1 (1:200, Cayman Chemical Co., Ann Arbor, MI, USA), and rabbit anti-actin IgG (1:5000, Sigma, Saint Louis, MO, USA). AB-coupled proteins were detected with horseradish peroxidase-coupled rabbit anti-goat IgG (Santa Cruz, 1:100,000 dilution) or goat anti-rabbit IgG (Amersham, 1:25,000 dilution) using enhanced chemiluminescence Western blotting substrate (Biozym Scientific GmbH, Rockford, USA). The quantification of the Western blots was performed using ImageJ. All Western blot experiments were carried out at least three times. 


\section{Cyclooxygenase activity assay}

To evaluate the effect of AM404 on COX enzymatic activity, an arachidonic acid assay was performed as previously described [27]. There are currently two well identified cyclooxygenase isoforms, named COX-1 and COX-2. The first one is constitutively expressed in almost every cell and COX-2, although can also be constitutive in some cells, is induced by cytokines and endotoxins [28, 29]. Under unstimulated conditions, primary microglial cells only express the COX-1 isoform [30]. Briefly, to measure COX-1 activity, primary rat microglial cells were plated in 24-well cell culture plates, and after $24 \mathrm{~h}$, the medium was removed and replaced with serum-free medium. AM404 $(0.1-10 \mu \mathrm{M})$ or selective COX1 inhibitors [acetylsalicylic acid (ASA, 50-100 $\mu \mathrm{M}$ ), irreversible inhibitor, or SC560 $(0.1-1 \mu \mathrm{M})$ reversible inhibitor] were added, and left for $15 \mathrm{~min}$. After that, $15 \mu \mathrm{M}$ of arachidonic acid were supplemented for another $15 \mathrm{~min}$. Supernatants were then collected and used for the determination of $\mathrm{PGE}_{2}$.

We also investigated the effects of AM404 on microglial total COX (COX-1 + COX-2) enzymatic activity, which mainly determined COX-2 mediated $\mathrm{PGE}_{2}$ production. Since we also have a slight contribution of COX-1 activity in this assay, we titled as COX-1 + COX-2 activity.

The COX-1 + COX-2 activity assay was conducted exactly as mentioned before with pre-incubation with LPS (10 ng/ $\mathrm{mL}$ ) for $24 \mathrm{~h}$ to induce COX-2 synthesis and using diclofenac sodium (preferential COX-2 inhibitor, 1-10 $\mu \mathrm{M}$ ).

Furthermore, to understand if the effects of AM404 in COX-1 and COX-1+COX-2 activities produce a reversible or irreversible inhibition, the assays were evaluated with some modifications. For COX-1 activity, the drugs were incubated for $60 \mathrm{~min}$, after the wells were washed three times with PBS $37{ }^{\circ} \mathrm{C}$ and incubated for $3 \mathrm{~h}$ with serumfree medium. Then, medium was changed and added $15 \mu \mathrm{M}$ arachidonic acid for $15 \mathrm{~min}$. For total COX activity, primary rat microglial cells were first pre-incubated with LPS $(10 \mathrm{ng} / \mathrm{mL})$ for $24 \mathrm{~h}$ and then follow the same procedure describe for COX-1. Finally, the supernatants were collected for determination of $\mathrm{PGE}_{2}$.

\section{Data analysis}

Results were converted into percentage values of LPS and presented as mean \pm SEM. Data was analyzed using one-way analysis of variance (ANOVA) followed by Newman-Keuls post-test. The level of statistical significance was set as ${ }^{*} p<0.05, " p<0.01$, and ${ }^{* * * *} p<0.001$. Graph Pad Prism (Graph Pad Software, San Diego, CA) was used for performing all statistical analysis.

\section{Results}

\section{AM404 inhibited LPS-induced $\mathrm{PGE}_{2}$ release by microglia} in OHSC

We first investigated whether AM404 reduces LPS-induced $\mathrm{PGE}_{2}$ release in organotypic hippocampal slices cultures
(OHSCs). As shown in Fig. 1, the production of $\mathrm{PGE}_{2}$ after $24 \mathrm{~h}$ was increased after LPS stimulation and AM404 $50 \mu \mathrm{M}$ prevented the synthesis of $\mathrm{PGE}_{2}$ in OHSC (Fig. 1). Furthermore, to determine the involvement of microglia in LPS-mediated $\mathrm{PGE}_{2}$ levels in OHSC, we depleted these cells by using a liposome-encapsulated clodronate solution (Lip-CL) as previously demonstrated [22]. Incubation of the cells with Lip-CL reduced the microglia population to less than $5 \%$, but not affecting astrocytes and neurons [22, 24] (Additional file 1). After the depletion of microglia in OHSC, a potent reduction on $\mathrm{PGE}_{2}$ release was observed after stimulation with LPS (Fig. 1, black bars), demonstrating that the PGE ${ }_{2}$ inducing effect of LPS directly depends of microglial cells.

\section{AM404 inhibited LPS-induced $\mathrm{PGE}_{2}$ release in primary microglial cell cultures}

To study the effects of AM404 in microglial cells, we investigated whether AM404 reduces LPS-induced $\mathrm{PGE}_{2}$ release in primary mice or rat microglial cell cultures. As shown in Fig. 2, activation of microglial cells with LPS increased the production of $\mathrm{PGE}_{2}$ after $24 \mathrm{~h}$. Pretreatment with AM404 $(1-10 \quad \mu \mathrm{M})$ prevented the increase of $\mathrm{PGE}_{2}$ levels in a concentration-dependent manner in both cultures (Fig. 2a-b). Since the effect on cultures from different species was similar, the following experiments were performed in primary microglial cells cultures from rats.

To exclude that the observed inhibitory effects of AM404 is due to reduced cell viability, a cytotoxicity assay was performed. As shown in Additional file 2,

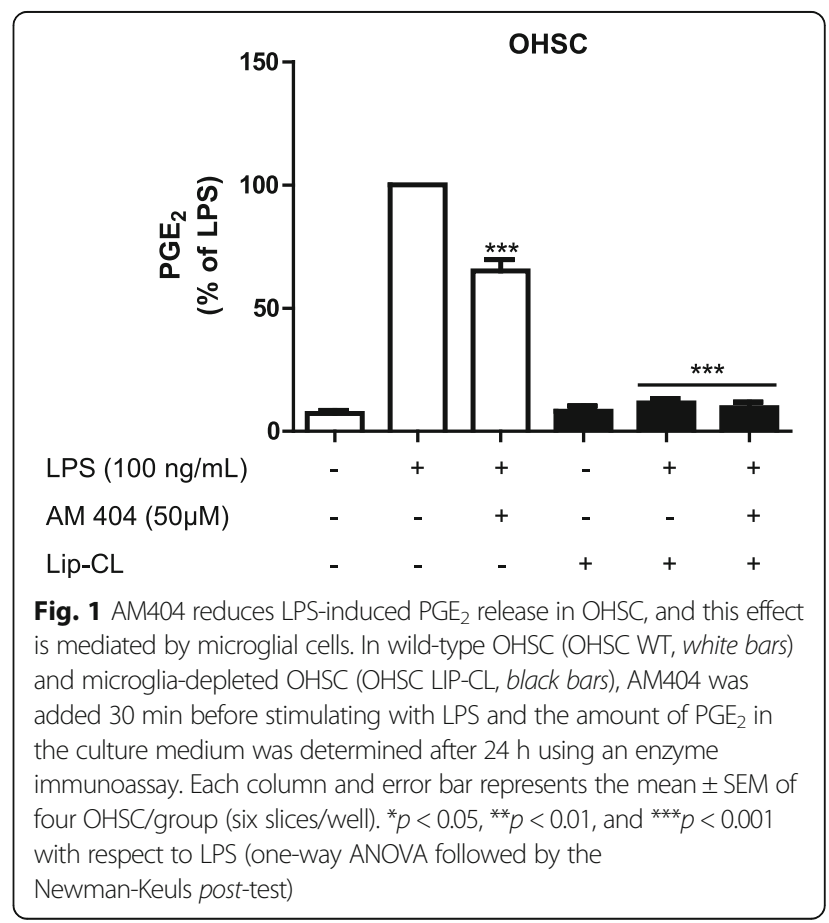



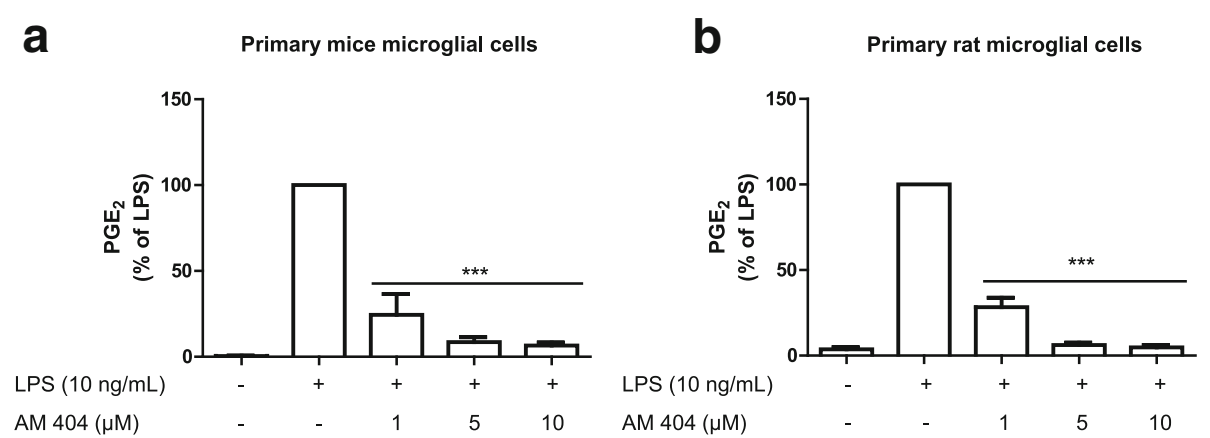

Fig. 2 AM404 reduces LPS-induced PGE $_{2}$ release in primary mice (a) and rat (b) microglial cells. AM404 was added 30 min before stimulating microglia with LPS and the amount of $\mathrm{PGE}_{2}$ in the culture medium was determined after $24 \mathrm{~h}$ using an enzyme immunoassay. Each column and error bar represent the mean \pm S.E.M. of 5 new cultures / group. ${ }^{* *} p<0.001$ with respect to LPS (One-way ANOVA followed by the NewmanKeuls post-test)

AM404 did not show any significant cytotoxicity in rat microglial cells at the concentrations used.

\section{The effect of AM404 on reduction of LPS-induced $\mathrm{PGE}_{2}$} release is independent of $\mathrm{CB} 1$ or TRPV1 receptors

AM404 is described as an agonist of TRPV1 [8] and CB1 receptors $[3,9]$. We therefore aimed to investigate whether AM404 reduced $\mathrm{PGE}_{2}$ release (Fig. 2) is mediated by one or both receptors. To this end, AM251 (CB1 antagonist) or capsazepine (TRPV antagonist) were added $30 \mathrm{~min}$ before AM404 and LPS treatment. As shown in Fig. 3a, the antagonism of CB1 with AM251 (10 $\mu \mathrm{M},-30 \mathrm{~min})$ or TRPV with capsazepine $(10 \mu \mathrm{M},-30 \mathrm{~min})$ did not affect the inhibitory effects of AM404 on $\mathrm{PGE}_{2}$ levels. Moreover, AM404 (1, 5 or $10 \mu \mathrm{M})$ prevented the increase in $\mathrm{PGE}_{2}$ induced by LPS in primary microglia from $\mathrm{TRPV}^{-/-}$knockout mice underlying the non-involvement of TRPV1 (Fig. 3b).

\section{AM404 reduced LPS-induced $\mathrm{PGD}_{2}$ and 8 -isoprostane release in primary rat microglial cell cultures}

Subsequently, we tested the effect of AM404 pretreatment on LPS-induced $\mathrm{PGD}_{2}$ release in primary rat microglia. As observed in Fig. 4a, the pre-treatment with AM404 $(0.1-10 \mu \mathrm{M})$ statistically prevented the $\mathrm{PGD}_{2}$ release in a concentration-dependent manner.

Next, we evaluated the effect of AM404 on the formation of reactive oxygen species in LPS-activated microglia. 8-iso- $\mathrm{PGF}_{2 \alpha}$ is produced by the non-enzymatic peroxidation of arachidonic acid in membrane phospholipids and is considered a reliable and highly sensitive marker to assess oxidative stress [31]. As shown in Fig. 4b, stimulation of microglial cells with LPS increased 8 -iso-PGF ${ }_{2 \alpha}$ levels, which were potently and dose-dependently prevented by pre-treatment with AM404 (0.1-10 $\mu \mathrm{M})$.

\section{AM404 reduced COX-2 but not mPGES-1 protein levels in} primary rat microglial cell culture

One of the mechanism by which AM404 might reduce prostaglandin levels is the reduction of the expression and synthesis of the enzymes responsible for their synthesis. Thus, we studied whether AM404 affected the synthesis of COX-2 and mPGES-1 in LPS-stimulated rat primary microglial culture. Our data showed that after

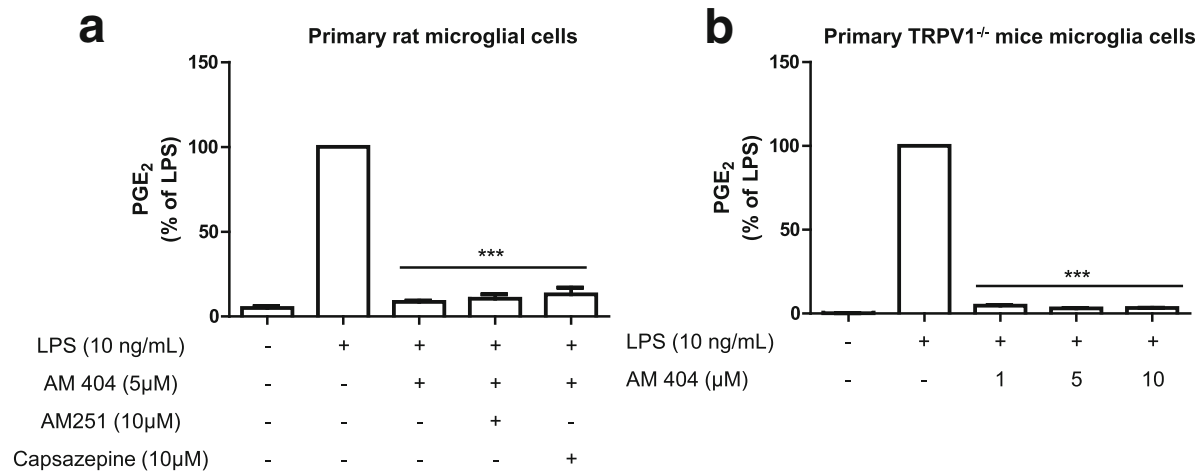

Fig. 3 Reduction of LPS-induced PGE 2 release by AM404 does not involve the CB1 or TRPV1 receptors. Antagonists of the CB1 (AM251) or TRPV1 receptor (Capsazepine) were used before AM404 and LPS treatment in primary rat microglial cells (a). Effects of AM404 in LPS-treated primary TRPV $1^{-/-}$knockout mice microglia cells (b). ${ }^{* *} p<0.001$ with respect to LPS (one-way ANOVA followed by the Newman-Keuls post-test, three new cultures/group) 



Fig. 4 AM404 concentration dependently reduces LPS-induced $\mathrm{PGD}_{2}(\mathbf{a})$ and 8-isoprostane (b) release after LPS stimulation in primary rat microglial cells. AM404 was added 30 min before stimulating with LPS, and the amount of $\mathrm{PGD}_{2}(\mathbf{a})$ and 8-iso-PGF $2 \alpha(\mathbf{b})$ in the culture medium were determined after $24 \mathrm{~h}$ using an enzyme immunoassay. Each column and error bar represents the mean \pm SEM of five new cultures/group. ${ }^{*} p<0.05,{ }^{* *} p<0.01$, and ${ }^{* *} p<0.001$ with respect to LPS (one-way ANOVA followed by the Newman-Keuls post-test)

$24 \mathrm{~h}$ of LPS stimulation, AM404 $(0.1-10 \mu \mathrm{M})$ weakly but significantly reduced the protein levels of LPSinduced COX-2, but it did not affect the synthesis of mPGES-1 increased by LPS (Fig. 5).

\section{AM404 decreased COX activity in primary rat microglial cell culture}

Since AM404 only weakly affected the protein levels of COX-2, we decided to evaluate its effect on COX enzyme



activity. First, we evaluated the effect on COX-1 activity and as shown in Fig. 6a, AM404 partially inhibited COX-1 activity (approximately 50\%) at the same concentrations that abolished $\mathrm{PGE}_{2}$ levels. As expected, both selected inhibitors of COX-1, SC-560, and ASA, potently reduced COX-1 activity.

As demonstrated in Fig. 6b, treatment with AM404 potently inhibited COX-2 activity in a concentrationdependent manner and in a similar profile as the inhibition of LPS-induced $\mathrm{PGE}_{2}$ in Fig. 2b.

\section{AM404 reversibly decreased COX activity in primary rat microglial cell culture}

To evaluate if the inhibition of COX activity is a reversible or irreversible effect, we removed the AM404 by washing the cultures several times as described in "Methods." As shown in Fig. 7a, partial inhibition of COX-1 activity by AM404 was abolished after this procedure, and the same effect was observed by SC-560, a reversible inhibitor of COX-1. In contrast, since ASA is an irreversible inhibitor COX-1, the inhibition of the enzyme activity induced by this drug was persistent (Fig. 7a). The same reversible effect of AM404 was observed on the inhibition of COX-2 activity, but in contrast, a high concentration of ASA persistently inhibited the enzyme activity (Fig. 7b).

\section{Discussion}

In the present study, we demonstrated that the acetaminophen metabolite, AM404, reduces inflammatory mediators of the arachidonic acid cascade in OHSC and primary microglial cells. We show here that AM404 decreased the release of $\mathrm{PGD}_{2}, \mathrm{PGE}_{2}$, and 8-iso- $\mathrm{PGF}_{2 \alpha}$, by a mechanism independent of TRPV1 or CB1 receptors, but by reversibly inhibiting COX-1 and COX-2 activity, as well as by slightly reducing the expression levels of COX-2 protein in microglia. 
Various studies have been performed to elucidate the mechanism of action of acetaminophen since it is one of the most prescribed and consumed drugs in the world for mild to moderate pain relieve and fever reduction, and its intracellular pathways are not fully understood. Acetaminophen produces a weak inhibition of COX, and it has been proposed that acetaminophen acts on COX-3, a brain-specific isoform of $\mathrm{COX}$ and slice variant of constitutive enzyme COX-1 [32, 33]. Indeed, many studies have demonstrated its inhibitory effect on $\mathrm{PGE}_{2}$ production in the brain [1] and in primary microglial culture $[2,34]$. $\mathrm{PGE}_{2}$ is an important subproduct of the enzymatic action of COX and a mediator of fever where its increase occurs in response to systemic pyrogen agents produced by infectious pathogens [35-38].

Högestätt et al. [3] and Murasamatsu et al. [7] have demonstrated that milligrams of paracetamol are converted in picograms of AM404 into the CNS of rodents, which could induce different pharmacological effects, including the effects on COX expression and activity. However, the correlation between in vitro and in vivo studies is complex due to different pharmacokinetic and micro-environment parameters to be considered. In the meantime, it has been suggested that AM404 is the active metabolite of acetaminophen and is responsible for its analgesic activity $[3,6,7]$. The involvement of AM404 in analgesia has been well established in animal models of nociceptive and neuropathic pain [14-16, 39]. In addition, the effect of AM404 in modulating peripheral inflammation $[14,19,21]$ and in immune cell culture $[3,20]$ has been described. However, the direct effect of AM404 in neuroinflammation, especially in microglia, is still poorly understood.

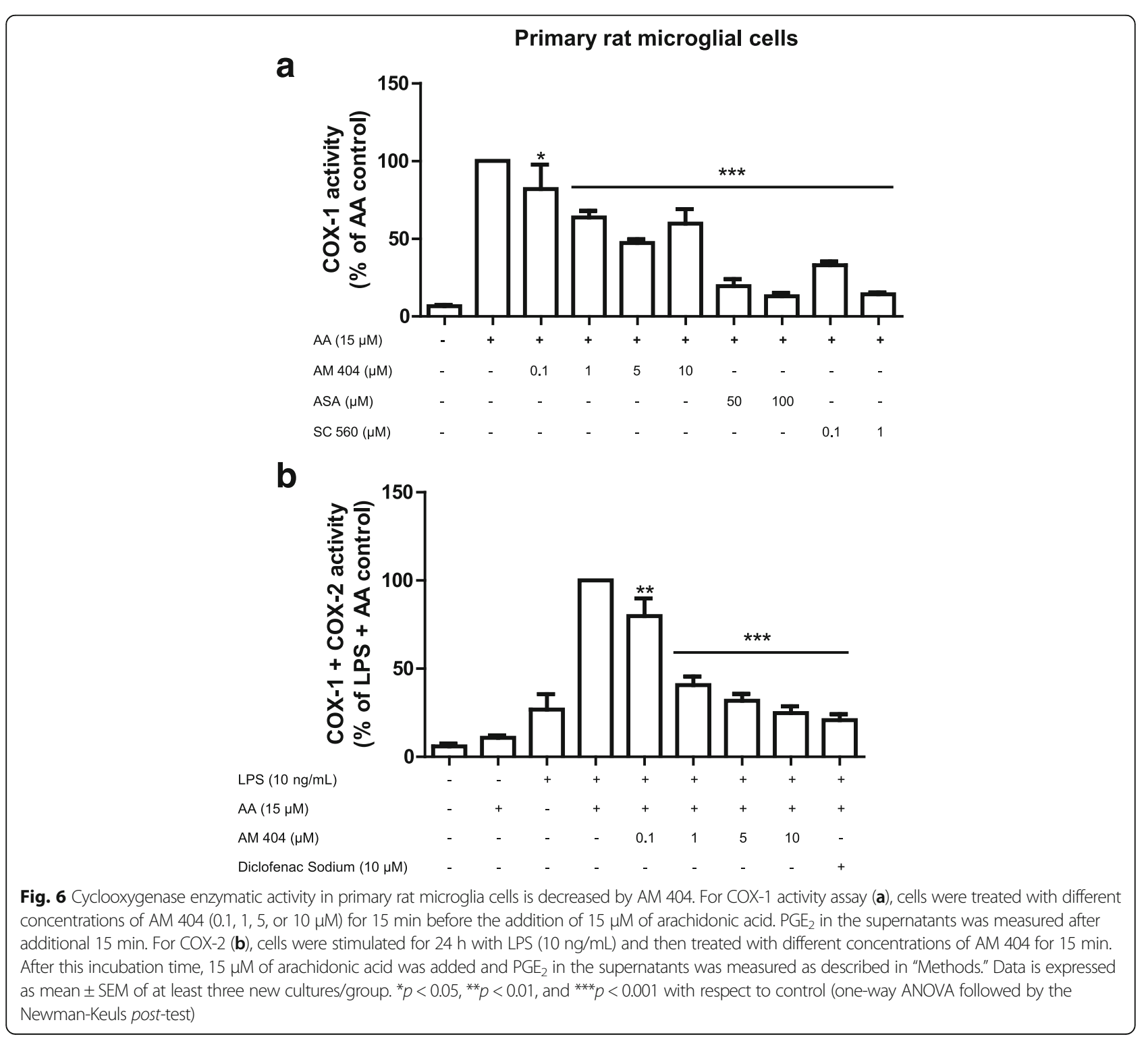


a

\section{Primary rat microglial cells}

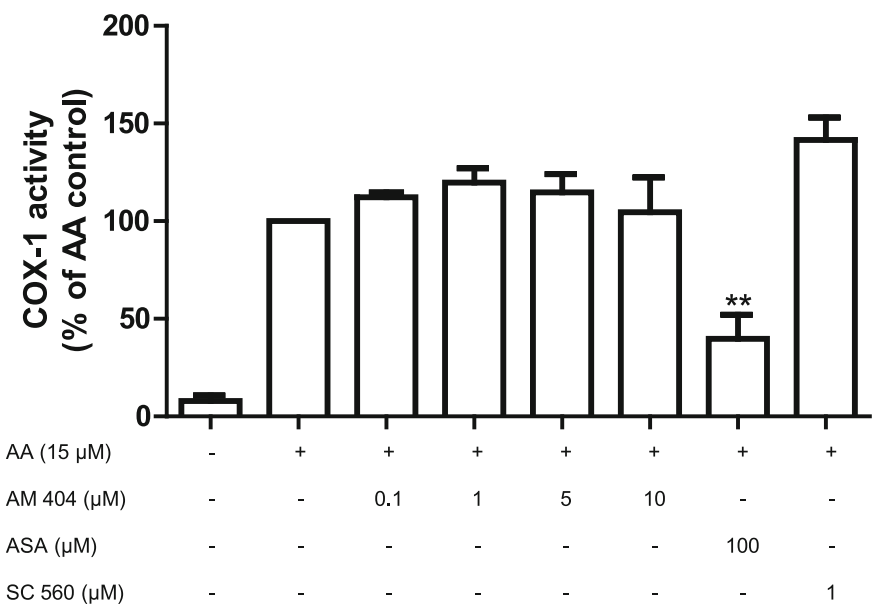

b

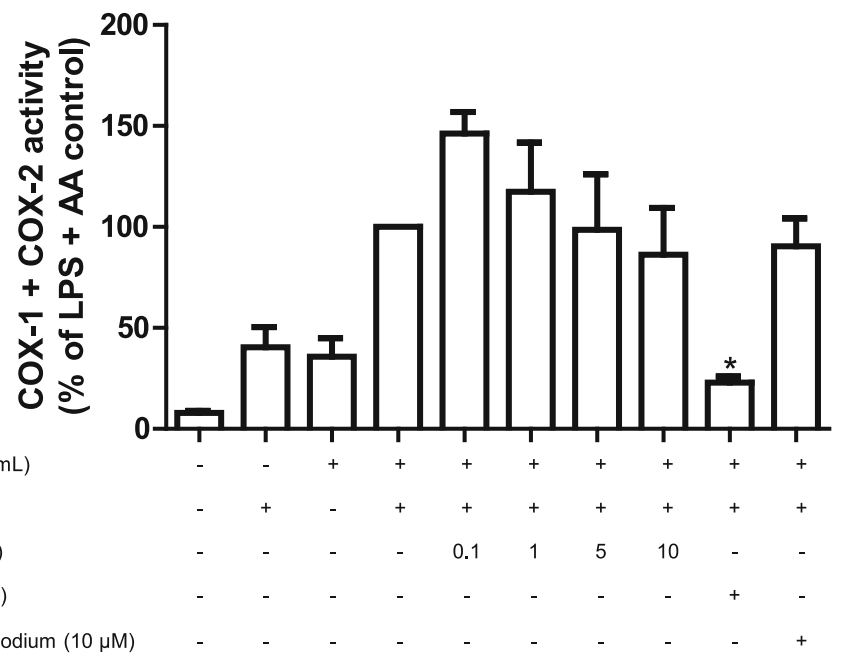

Fig. 7 Reversibility of the AM404 mediated inhibition of COX-1 (a) and COX-2 (b) activity in primary rat microglia cells. a The cells were treated with different concentrations of AM $404(0.1,1,5$, or $10 \mu M)$ for 60 min. For COX-2 (b)), cells were stimulated for $24 \mathrm{~h}$ with LPS (10 ng/mL) and then treated with different concentrations of AM 404 for $60 \mathrm{~min}$. After this incubation time, $\mathbf{a}$ and $\mathbf{b}$ were washed three times with DPBS $37^{\circ} \mathrm{C}$ and incubated for $3 \mathrm{~h}$ with serum-free medium. Fifteen micromolar of arachidonic acid was added, and PGE $E_{2}$ in the supernatants was measured as described in "Methods." Data are expressed as mean \pm SEM of at least four new cultures/group). ${ }^{*} p<0.05$ and ${ }^{* *} p<0.01$ with respect to control (one-way ANOVA followed by the Newman-Keuls post-test)

OHSC is a well-established brain tissue model maintaining the main architecture of the cells, and its complex system provides a good tool to understand cellular and molecular processes of the brain in vitro [40, 41]. Our results in OHSC demonstrated that the AM404 inhibited the release of $\mathrm{PGE}_{2}$ induced by LPS stimulation, and by depleting the microglial cells from OHSC, the levels of $\mathrm{PGE}_{2}$ after stimulation with LPS were completely abolished. As known, microglial cells are the resident macrophages of the CNS and the most important source of $\mathrm{PGE}_{2}$ in neuroinflammation. It has been demonstrated before that in primary microglial cells stimulated with LPS, $\mathrm{PGE}_{2}$ and COX-2 expression are strongly increased [42-44].

Thus, to elucidate the mechanisms by which AM404 affects these cells, we continued our further experiments with primary microglial cells (mouse and rat) treated with LPS. Studies in primary cell cultures allowed us to better understanding of the mechanism of pure microglia as a result of distinct stimulations. It has been reported that the process of microglia isolation may lead to their activation $[45,46]$. However, we do not observe an activation status in respect of inflammatory parameters. After LPS stimulation, we observe comparable data in cultivated microglia mono-cultures and in organotypic slice culture models, where LPS-induced $\mathrm{PGE}_{2}$ release, and therefore believe that our results are robust in both models, although the morphological and biochemical status of microglia may depend on the cells that are also present in the cultured [46-50]. The pre-treatment with AM404 potently prevented the increase on $\mathrm{PGE}_{2}$ 
release stimulated by LPS from both species. This effect of AM404 on downregulating $\mathrm{PGE}_{2}$ release provides us an important contribution to explain the mechanism by which paracetamol might control fever. The involvement of AM404 in inhibition of LPS-induced $\mathrm{PGE}_{2}$ formation in RAW264.7 macrophages was also described by Högestätt and colleagues [3].

AM404 modulates the endocannabinoid system by acting via TRPV1 and CB1 receptors, and it increased the viability of anandamide in the medium by blocking AMT $[10,11]$. The involvement of cannabinoids in inflammation has been shown in different models and demonstrated some evidences for anti-inflammatory effects [51, 52]. Furthermore, many studies have described the participation of cannabinoids on immune modulation [53-56]. Immune cells express the cannabinoid receptors type 1 and type 2 , albeit CB2 appears to be the predominant isoform [57, 58]. In microglia, the expression and the amount of $\mathrm{CB}$ receptors may change depending on the type of neuropathology. However, it has been reported that rat and mouse primary microglia cultures express both $\mathrm{CB} 1$ and $\mathrm{CB} 2$ receptor mRNA and protein [52]. Moreover, microglia can also express TRPV1 that mediate some endocannabinoid actions $[59,60]$. However, the involvement of TRPV1 and CB1 receptors in AM404 effects is still not completely elucidated since the present data are controversial. Roche et al. [19] have shown that the effect of AM404 on the increase of circulating TNF- $\alpha$ after LPS injection was blocked by SB366791 (TRPV1 antagonist) and AM251 (CB1 antagonist) and the decrease on IL-1ß was attenuated only by AM251, but neither of these antagonists altered the effect of AM404 on the decrease of IL-6. In addition, in a model of cerebral ischemia in gerbils, AM404 reduced neuronal damage, and this effect was reversed by AM251, but not by capsazepine [61]. In the present study, we evaluated the involvement of TRPV1 and CB1 receptors in the modulation of $\mathrm{PGE}_{2}$ release by $\mathrm{AM} 404$, and our findings showed that the mechanisms underlying the anti-inflammatory effect of AM404 in CNS cells did not involve TRPV1 and CB1 receptors, additionally supported by using TRPV1 knockout mice.

Free radicals also contribute to the inflammatory process by metabolizing arachidonic acid to isoprostanes. The involvement of AM404 on the decrease of oxidative stress has been proposed by the presence of a phenolic group in its structure $[17,18]$, and Costa et al. [14] proved in a model of neuropathic pain that AM404 prevented the overproduction of nitic oxide (NO). In addition, García-Arencibia and collaborators (2007) have suggested the antioxidant effect of AM404 as one of the neuroprotective mechanism of AM404 in a Parkinson's disease [62] model. In accordance with the literature, we showed that AM404 prevented the formation of reactive oxygen species in primary microglial cells.
In order to understand the mechanism by which prostaglandins are reduced by AM404, we tested the hypothesis that AM404 inhibits COX activity as described in a monocyte cell line stimulated with LPS $(1 \mu \mathrm{g} / \mathrm{mL})$ [3]. Indeed, we demonstrated that AM404 inhibited COX-1 and COX-2 activities. Furthermore, the inhibition of COX seems to be reversible. Additionally, this compound slightly reduced COX-2 protein levels induced by LPS in microglia. Thus, different mechanisms may participate in the reduction of prostaglandin levels mediated by AM404.

\section{Conclusions}

In summary, we provided evidence that AM404 interferes in several steps of the synthesis of prostaglandins in LPS-activated microglia. This study provides new significant insights on the potential anti-inflammatory activity of AM404 and new mechanisms in respect of the central action of acetaminophen in the modulation of prostaglandin production by microglia.

\section{Additional files}

Additional file 1: Representative images of the immunolabeled OHSC with Iba-1 (red), GFAP (green), and DAPI (blue) in $200 \mu \mathrm{m}$. (A-E) Wild-type OHSC (OHSC WT) and (F-I) microglia-depleted OHSC (OHSC LIP-CL). (PDF 228 kb)

Additional file 2: Effects of AM404 on cell viability in primary rat microglia cells. AM404 was added 30 min before stimulating the cells with LPS for $24 \mathrm{~h}$, and cell death was measured by the intensity of the fluorescence emission in the culture using the CellTox ${ }^{\mathrm{TM}}$ Green Cytotoxicity assay kit. Each column and error bar represents the percentage of fluorescence (100\% for just microglia cells). ${ }^{* * *} p<0.001$ with respect to just microglia cells (One-way ANOVA followed by the Newman-Keuls post-test). (PDF 16 kb)

\footnotetext{
Abbreviations

8-iso-PGF $2 a$ : 8-Iso-prostaglandin $\mathrm{F}_{2 a}$; $\mathrm{AA}$ : Arachidonic acid; $\mathrm{AB}$ : Antibody; AM404: N-arachidonoylphenolamine; AMT: Anandamide membrane transporter; AP-1: Activator protein 1; ASA: Acetylsalicylic acid; BCA: Bicinchoninic acid method; BME: Basal medium without glutamate; CB1: Cannabinoid receptor type 1; CNS: Central nervous system; COX: Cyclooxygenase; DAPI: 4',6-Diamidino-2-phenylindole; DMEM: Dulbecco's Modified Eagle's Medium; DMSO: Dimethyl sulfoxide; DPBS: Dulbecco's Phosphate Buffered Saline; ETOH: Ethanol; FAAH: Fatty acid amide hydrolase; GFAP: Glial fibrillary acidic protein; Iba-1: Ionized calciumbinding adapter molecule 1; IL: Interleukin; Lip-CL: Liposome-encapsulated clodronate; LPS: Lipopolysaccharide; MEM: Minimum essential medium; mPGES: Microsomal prostaglandin E synthase; NFAT: Nuclear factor of activated T cells; NF-kappaB: Nuclear factor kappa-light-chain-enhancer of activated B cells; NGS: Normal goat serum; OHSC: Organotypic hippocampal slices culture; OTC: Over-the-counter; PFA: Paraformaldehyde; PG: Prostaglandin; PGHS: Prostaglandin endoperoxide synthase; PVDF: Polyvinylidene fluoride; SDS-PAGE: Sodium dodecyl sulfatepolyacrylamide gel electrophoresis; TCR: T cell receptor; TLR4: Toll-like receptor 4; TNF: Tumor necrosis factor; TRPV1: Transient receptor potential vanilloid type $1 ; \mathrm{WT}$ : Wild-type
}

\section{Acknowledgements}

The skillful technical assistance of Ulrike Götzinger-Berger and Brigitte Günter is greatly acknowledged. Soraya Wilke Saliba received a fellowship from CNPq/ CSF (Brasília/Brazil) and DAAD (Germany). Antônio Carlos Pinheiro de Oliveira acknowledges CNPq for the Research Productivity Fellowship (process number 309718/2015-5). The article processing charge was funded by the University of Freiburg in the funding programme Open Access Publishing. 


\section{Funding}

Soraya Wilke Saliba received a fellowship from CNPq/CSF (Brasília/Brazil) and DAAD (Germany). Antônio Carlos Pinheiro de Oliveira acknowledges CNPq for the Research Productivity Fellowship (process number 309718/2015-5).

\section{Availability of data and materials}

All data are provided in the manuscript and in the additional files.

\section{Authors' contributions}

SWS, ACPdO, and BLF participated in research design. The experiments were performed by SWS, EF, and JD. Data were analyzed by SWS, EF, and JD. SWS, ARM, ACPdO, and BLF wrote or contributed to the writing of the manuscript. In addition, SWS, ARM, JCP, EM, ACPdO, and BLF reviewed the data and discussed the manuscript. All authors have read and approved the final version of the manuscript.

\section{Ethics approval and consent to participate}

All procedures used in this study were approved and performed according to the guidelines of ethics committee of University of Freiburg Medical School.

\section{Consent for publication}

Not applicable.

\section{Competing interests}

The authors declare that they have no competing interests.

\section{Publisher's Note}

Springer Nature remains neutral with regard to jurisdictional claims in published maps and institutional affiliations.

\section{Author details}

${ }^{1}$ Department of Psychiatry and Psychotherapy, Laboratory of Translational Psychiatry, Faculty of Medicine, Medical Center - University of Freiburg, Hauptstr. 5, 79104 Freiburg, Germany. ${ }^{2}$ Faculty of Biology, University of Freiburg, Freiburg, Germany. ${ }^{3}$ Laboratory of Hepatic Encephalopathy and Portal Hypertension, Center of Applied and Experimental Pathology, University of Buenos Aires, Buenos Aires, Argentina. ${ }^{4}$ Departamento de Biología Celular, Instituto Maimónides de Investigación Biomédica de Córdoba, Hospital Universitario Reina Sofía, Fisiología e Inmunología, Universidad de Córdoba, Córdoba, Spain. ${ }^{5}$ Department of Pharmacology, Universidade Federal de Minas Gerais, Belo Horizonte, MG, Brazil.

\section{Received: 18 August 2017 Accepted: 27 November 2017}

\section{Published online: 13 December 2017}

\section{References}

1. Flower RJ, Vane JR. Inhibition of prostaglandin synthetase in brain explains the anti-pyretic activity of paracetamol (4-acetamidophenol). Nature. 1972; 240:410-1

2. Greco A, Ajmone-Cat MA, Nicolini A, Sciulli MG, Minghetti L. Paracetamol effectively reduces prostaglandin E2 synthesis in brain macrophages by inhibiting enzymatic activity of cyclooxygenase but not phospholipase and prostaglandin E synthase. J Neurosci Res. 2003;71:844-52

3. Högestätt ED, Jönsson BAG, Ermund A, Andersson DA, Björk H, Alexander JP, et al. Conversion of acetaminophen to the bioactive $\mathrm{N}$-acylphenolamine AM404 via fatty acid amide hydrolase-dependent arachidonic acid conjugation in the nervous system. J Biol Chem. 2005;280:31405-12.

4. Bertolini A, Ferrari A, Ottani A, Guerzoni S, Tacchi R, Leone S. Paracetamol: new vistas of an old drug. CNS Drug Rev. 2006;12:250-75.

5. Bisogno T, De Petrocellis L, Di Marzo V. Fatty acid amide hydrolase, an enzyme with many bioactive substrates. Possible therapeutic implications. Curr Pharm Des. 2002:8:533-47.

6. Mallet C, Daulhac L, Bonnefont J, Ledent C, Etienne M, Chapuy E, et al. Endocannabinoid and serotonergic systems are needed for acetaminopheninduced analgesia. Pain. 2008;139:190-200.

7. Muramatsu S, Shiraishi S, Miyano K, Sudo Y, Toda A, Mogi M, et al. Metabolism of AM404 From Acetaminophen at Human Therapeutic Dosages in the Rat Brain. Anesth Pain Med. 2016;6(1):e32873. doi: 10.5812/ aapm.32873.
8. Zygmunt PM, Chuang H, Movahed P, Julius D, Högestätt ED. The anandamide transport inhibitor AM404 activates vanilloid receptors. Eur J Pharmacol. 2000;396:39-42.

9. Ottani A, Leone S, Sandrini M, Ferrari A, Bertolini A. The analgesic activity of paracetamol is prevented by the blockade of cannabinoid CB1 receptors. Eur J Pharmacol. 2006:531:280-1.

10. Beltramo M, Stella N, Calignano A, Lin SY, Makriyannis A, Piomelli D. Functional role of high-affinity anandamide transport, as revealed by selective inhibition. Science. 1997;277:1094-7.

11. Giuffrida A, Rodriguez de Fonseca F, Nava F, Loubet-Lescoulié P, Piomelli D. Elevated circulating levels of anandamide after administration of the transport inhibitor, AM404. Eur J Pharmacol. 2000;408:161-8.

12. Fegley D, Kathuria S, Mercier R, Li C, Goutopoulos A, Makriyannis A, et al. Anandamide transport is independent of fatty-acid amide hydrolase activity and is blocked by the hydrolysis-resistant inhibitor AM1172. Proc Natl Acad Sci U S A. 2004;101:8756-61.

13. Rawls S, Ding Z, Cowan A. Role of TRPV1 and cannabinoid CB1 receptors in AM 404-evoked hypothermia in rats. Pharmacol Biochem Behav. 2006:83:508-16.

14. Costa B, Siniscalco D, Trovato AE, Comelli F, Sotgiu ML, Colleoni M, et al. AM404, an inhibitor of anandamide uptake, prevents pain behaviour and modulates cytokine and apoptotic pathways in a rat model of neuropathic pain: AM404 relieves neuropathic pain. Br J Pharmacol. 2009;148:1022-32

15. La Rana G, Russo R, Campolongo P, Bortolato M, Mangieri RA, Cuomo V, et al. Modulation of neuropathic and inflammatory pain by the endocannabinoid transport inhibitor AM404 [N-(4-hydroxyphenyl)-eicosa5,8,11,14-tetraenamide]. J Pharmacol Exp Ther. 2006:317:1365-71.

16. Mitchell VA, Greenwood R, Jayamanne A, Vaughan CW. Actions of the endocannabinoid transport inhibitor AM404 in neuropathic and inflammatory pain models. Clin Exp Pharmacol Physiol. 2007;34:1186-90.

17. Barber SC, Higginbottom A, Mead RJ, Barber S, Shaw PJ. An in vitro screening cascade to identify neuroprotective antioxidants in ALS. Free Radic Biol Med. 2009:46:1127-38.

18. Marsicano G, Moosmann B, Hermann H, Lutz B, Behl C. Neuroprotective properties of cannabinoids against oxidative stress: role of the cannabinoid receptor CB1. J Neurochem. 2002;80:448-56.

19. Roche M, Kelly JP, O'Driscoll M, Finn DP. Augmentation of endogenous cannabinoid tone modulates lipopolysaccharide-induced alterations in circulating cytokine levels in rats. Immunology. 2008;125:263-71.

20. Caballero FJ, Navarrete CM, Hess S, Fiebich BL, Appendino G, Macho A, et al. The acetaminophen-derived bioactive $\mathrm{N}$-acylphenolamine AM404 inhibits NFAT by targeting nuclear regulatory events. Biochem Pharmacol. 2007;73: 1013-23.

21. Turman MV, Kingsley PJ, Marnett $\sqcup$. Characterization of an AM404 analogue, $\mathrm{N}$-(3-hydroxyphenyl)arachidonoylamide, as a substrate and inactivator of prostaglandin endoperoxide synthase. Biochemistry (Mosc). 2009:48:12233-41.

22. Vinet J, Weering HR, Heinrich A, Kälin RE, Wegner A, Brouwer N, Heppner FL, Rooijen Nv, Boddeke HW, Biber K. Neuroprotective function for ramified microglia in hippocampal excitotoxicity. J Neuroinflammation. 2012;9:27. doi: 10.1186/1742-2094-9-27.

23. Karanian DA, Brown QB, Makriyannis A, Kosten TA, Bahr BA. Dual modulation of endocannabinoid transport and fatty acid amide hydrolase protects against excitotoxicity. J Neurosci. 2005;25:7813-20.

24. Markovic DS, Glass R, Synowitz M, Rooijen van N, Kettenmann H. Microglia stimulate the invasiveness of glioma cells by increasing the activity of metalloprotease-2. J Neuropathol Exp Neurol. 2005;64:754-62.

25. de Oliveira AC, Yousif NM, Bhatia HS, Hermanek J, Huell M, Fiebich BL. Poly(l: C) increases the expression of mPGES-1 and COX-2 in rat primary microglia. J Neuroinflammation. 2016:13:11. doi: 10.1186/s12974-015-0473-7.

26. Seregi A, Keller M, Jackisch R, Hertting G. Comparison of the prostanoid synthesizing capacity in homogenates from primary neuronal and astroglial cell cultures. Biochem Pharmacol. 1984;33:3315-8.

27. Fiebich BL, Lieb K, Kammerer N, Hüll M. Synergistic inhibitory effect of ascorbic acid and acetylsalicylic acid on prostaglandin E2 release in primary rat microglia: inhibition of PGE2 synthesis by ascorbic acid. J Neurochem. 2004;86:173-8

28. Samuelsson B, Granstrom E, Green K, Hamberg M, Hammarstrom S. Prostaglandins. Annu Rev Biochem. 1975;44:669-95.

29. Sigal E. The molecular biology of mammalian arachidonic acid metabolism. Am J Phys. 1991;260:L13-28. 
30. Akundi RS, Candelario-Jalil E, Hess S, Hüll M, Lieb K, Gebicke-Haerter PJ, et al. Signal transduction pathways regulating cyclooxygenase-2 in lipopolysaccharide-activated primary rat microglia. Glia. 2005;51:199-208.

31. Morrow JD, Hill KE, Burk RF, Nammour TM, Badr KF, Roberts LJ. A series of prostaglandin F2-like compounds are produced in vivo in humans by a non-cyclooxygenase, free radical-catalyzed mechanism. Proc Natl Acad Sci U S A. 1990;87:9383-7.

32. Botting R, Ayoub SS. COX-3 and the mechanism of action of paracetamol/ acetaminophen. Prostaglandins Leukot Essent Fatty Acids. 2005;72:85-7.

33. Chandrasekharan NV, Dai H, Roos KLT, Evanson NK, Tomsik J, Elton TS, et al. COX-3, a cyclooxygenase-1 variant inhibited by acetaminophen and other analgesic/antipyretic drugs: cloning, structure, and expression. Proc Natl Acad Sci U S A. 2002;99:13926-31.

34. Fiebich BL, Lieb K, Hüll M, Aicher B, van Ryn J, Pairet M, et al. Effects of caffeine and paracetamol alone or in combination with acetylsalicylic acid on prostaglandin E(2) synthesis in rat microglial cells. Neuropharmacology. 2000;39:2205-13.

35. Bernheim HA. Is prostaglandin E2 involved in the pathogenesis of fever? Effects of interleukin-1 on the release of prostaglandins. Yale J Biol Med. 1986;59:151-8.

36. Coceani F, Bishai I, Lees J, Sirko S. Prostaglandin E2 and fever: a continuing debate. Yale J Biol Med. 1986;59:169-74.

37. Eskilsson A, Matsuwaki T, Shionoya K, Mirrasekhian E, Zajdel J, Schwaninger M, Engblom D, Blomqvist A. Immune-Induced Fever Is Dependent on Local But Not Generalized Prostaglandin E2 Synthesis in the Brain. J Neurosci. 2017;37(19):5035-5044. doi: 10.1523/JNEUROSCI.3846-16.2017.

38. Schuster VL. The ins and outs of prostaglandin E2 in fever. Temp Austin Tex. 2015:2:326-7.

39. Borsani E, Labanca M, Bianchi R, Rodella LF. AM404 decreases Fosimmunoreactivity in the spinal cord in a model of inflammatory pain. Brain Res. 2007;1152:87-94.

40. Cho S, Wood A, Bowlby MR. Brain slices as models for neurodegenerative disease and screening platforms to identify novel therapeutics. Curr Neuropharmacol. 2007;5:19-33.

41. Humpel C. Organotypic brain slice cultures: a review. Neuroscience. 2015; 305:86-98.

42. Bauer MK, Lieb K, Schulze-Osthoff K, Berger M, Gebicke-Haerter PJ, Bauer J, et al. Expression and regulation of cyclooxygenase-2 in rat microglia. Eur J Biochem. 1997;243:726-31.

43. Minghetti L, Levi G. Induction of prostanoid biosynthesis by bacterial lipopolysaccharide and isoproterenol in rat microglial cultures. J Neurochem. 1995;65:2690-8.

44. Slepko N, Minghetti L, Polazzi E, Nicolini A, Levi G. Reorientation of prostanoid production accompanies "activation" of adult microglial cells in culture. J Neurosci Res. 1997;49:292-300.

45. Eder C, Schilling T, Heinemann U, Haas D, Hailer N, Nitsch R. Morphological, immunophenotypical and electrophysiological properties of resting microglia in vitro: resting microglia in vitro. Eur J Neurosci. 1999;11:4251-61.

46. Duport S, Garthwaite J. Pathological consequences of inducible nitric oxide synthase expression in hippocampal slice cultures. Neuroscience. 2005;135:1155-66.

47. Papageorgiou IE, Lewen A, Galow LV, Cesetti T, Scheffel J, Regen T, et al. TLR4-activated microglia require IFN- $\gamma$ to induce severe neuronal dysfunction and death in situ. Proc Natl Acad Sci. 2016;113:212-7.

48. Vincent VA, Tilders FJ, Van Dam AM. Inhibition of endotoxin-induced nitric oxide synthase production in microglial cells by the presence of astroglial cells: a role for transforming growth factor beta. Glia. 1997;19:190-8.

49. Yang L, Tanaka J, Zhang B, Sakanaka M, Maeda N. Astrocytes modulate nitric oxide production by microglial cells through secretion of serine and glycine. Biochem Biophys Res Commun. 1998;251:277-82.

50. Solà C, Casal C, Tusell JM, Serratosa J. Astrocytes enhance lipopolysaccharide-induced nitric oxide production by microglial cells. Eur J Neurosci. 2002;16:1275-83.

51. M Saito V, M Rezende R, L Teixeira A. Cannabinoid modulation of neuroinflammatory disorders. Curr Neuropharmacol. 2012;10:159-66.

52. Walter L, Stella N. Cannabinoids and neuroinflammation. Br J Pharmacol. 2004;141:775-85.

53. Berdyshev EV. Cannabinoid receptors and the regulation of immune response. Chem Phys Lipids. 2000;108:169-90.
54. De Petrocellis L, Melck D, Bisogno T, Di Marzo V. Endocannabinoids and fatty acid amides in cancer, inflammation and related disorders. Chem Phys Lipids. 2000;108:191-209.

55. Kaminski NE. Regulation of the CAMP cascade, gene expression and immune function by cannabinoid receptors. J Neuroimmunol. 1998;83:124-32.

56. Parolaro D, Massi P, Rubino T, Monti E. Endocannabinoids in the immune system and cancer. Prostaglandins Leukot Essent Fatty Acids. 2002;66:319-32.

57. Carayon P, Marchand J, Dussossoy D, Deroca JM, Jbilo O, Bord A, et al. Modulation and functional involvement of CB2 peripheral cannabinoid receptors during B-cell differentiation. Blood. 1998;92:3605-15.

58. Munro S, Thomas KL, Abu-Shaar M. Molecular characterization of a peripheral receptor for cannabinoids. Nature. 1993;365:61-5.

59. $\mathrm{H}-\mathrm{C}$ L, Mackie K. An introduction to the endogenous cannabinoid system. Biol Psychiatry. 2016;79:516-25.

60. Stella N. Cannabinoid and cannabinoid-like receptors in microglia, astrocytes, and astrocytomas. Glia. 2010;58:1017-30.

61. Zani A, Braida D, Capurro V, Sala M. Delta9-tetrahydrocannabinol (THC) and AM 404 protect against cerebral ischaemia in gerbils through a mechanism involving cannabinoid and opioid receptors. Br J Pharmacol. 2007;152:1301-11.

62. García-Arencibia M, González S, de Lago E, Ramos JA, Mechoulam R, Fernández-Ruiz J. Evaluation of the neuroprotective effect of cannabinoids in a rat model of Parkinson's disease: importance of antioxidant and cannabinoid receptor-independent properties. Brain Res. 2007;1134(1):162-70.

\section{Submit your next manuscript to BioMed Central and we will help you at every step:}

- We accept pre-submission inquiries

- Our selector tool helps you to find the most relevant journal

- We provide round the clock customer support

- Convenient online submission

- Thorough peer review

- Inclusion in PubMed and all major indexing services

- Maximum visibility for your research

Submit your manuscript at www.biomedcentral.com/submit 